\title{
Optimal Locations of Bus Stops Connecting Subways near Urban Intersections
}

\author{
Yuan Cui, ${ }^{1,2}$ Shao-kuan Chen, ${ }^{1}$ Jian-feng Liu, ${ }^{3}$ and Wen-zheng Jia ${ }^{4}$ \\ ${ }^{1}$ MOE Key Laboratory for Urban Transportation Complex Systems Theory and Technology, \\ Beijing Jiaotong University, Beijing 100044, China \\ ${ }^{2}$ Transport Planning and Research Institute, Ministry of Transport, Beijing 100028, China \\ ${ }^{3}$ Beijing Transportation Research Center, Beijing 100073, China \\ ${ }^{4}$ China Urban Sustainable Transport Research Center, China Academy of Transportation Sciences, Beijing 100029, China
}

Correspondence should be addressed to Shao-kuan Chen; shkchen@bjtu.edu.cn

Received 20 July 2014; Revised 1 October 2014; Accepted 19 October 2014

Academic Editor: Wai Yuen Szeto

Copyright (C) 2015 Yuan Cui et al. This is an open access article distributed under the Creative Commons Attribution License, which permits unrestricted use, distribution, and reproduction in any medium, provided the original work is properly cited.

\begin{abstract}
Unsuitable locations of bus stops which provide feeder transportation connecting subways near urban intersections usually lead to the low efficiency of public transport and level of passenger service. A multiobjective optimization model to distribute such stop locations is proposed to attain the shortest total walk distance of passengers and minimum delay time of cars through intersections and travel time of buses. The Pareto frontier and optimal solutions for the proposed model are given by the distance-based and enumerative methods. The Xizhimen bus stop is selected to implement case studies for verifying the validity of the proposed model. The analysis of sensitivity on possible solutions is also carried out in the case studies. The results show that the proposed model is capable of optimizing the locations of bus stops connecting subways near intersections and helpful to improve the level of passengers service and operational efficiency of public transportation.
\end{abstract}

\section{Introduction}

The demand of urban traffic in China has been dramatically increasing with the rapid development of economy, urbanization, and mobilization for last decades. Moreover, severe traffic congestion is challenging to the operation and management of urban traffic. More people have realized that urban public transit is an effective way to mitigate traffic congestion and improve the sustainability of transport development.

Urban public transit is a highly complex system where urban railways and buses are crucial parts of the sustainably social development. Due to reliable running time, efficient transport service, and energy consumption, urban rail transit which can carry a great number of passengers has been playing a very important role as the skeleton of urban traffic system. The number of passengers served by the Beijing subway system has exceeded 10 million persons per day. The efficiency of urban rail transit depends not only on its operational performance but also on good cooperation with other transportation modes, especially with those buses which are able to provide feeder service for passengers arriving at or leaving urban rail stations.

Bus stops, as the connecting points between buses and urban rail transit services, are important spaces for passengers to alight or board [1]. According to the real situation of urban roads, the areas around intersections are suitable and convenient to arrival and leaving of passengers. Thus, the bus stops near intersections are often considerable for passengers transferring between urban rail transit and buses, which have a great impact on level of passenger service and attraction of public transit.

The bus stops connecting subways have some different characteristics, such as more bus routes and berths, longer bus stopping time for passengers to alight or board, larger ridership amount, and more complex passenger flow than common bus stops. If bus stops are not located correctly, they are likely to cause serious impacts on road traffic flow [2] and intersection capacity [3] and even become the bottlenecks of urban traffic systems [4]. 
Three major criteria, the efficiency, effectiveness, and equity of service, are employed to evaluate public systems [5]. The efficiency of service is defined as the ratio of LOS (level of service) to the cost of resource consumed and thus usually measured by its cost. The effectiveness of service shows what comfortable service public transport can provide. The equity of service requires an indiscrimination of transport supplies that different users can obtain. The above three criteria reflect the interests of different stakeholders involved in operators (bus companies), bus users (passengers), and other users (private cars, taxis), respectively, which are imported into this study.

\section{Literature Review}

The location of feeder bus stops near intersections is a hotspot in research of public transit which has been drawing the attention of researchers for decades. Those achievements have an important impact on the quality of service provided for passengers and the operation of bus vehicles.

There are two major types of studies relating tothe location optimization of bus stops. The first type investigates the layout of bus stops to cut down the cost of buses or overall transportation system. For example, by taking possible changes in demand into account, a bilevel optimization model for locating bus stops was developed to minimize the social cost of the overall transport system [6]. Hafezi and Ismail [7] analyzed the efficiency of bus operation where the studies on bus stop location at three points including near-side, far-side, and mid-block were considered. Li [8] established a model that lists the stops in the order that they appear after organizing bus stops by routes and then transformed the problem of matching bus stops into a shortest path problem. Similar research was also found in the work of $\mathrm{Hu}$ et al. [9] which attempted to analyze the characteristics of urban rail transit and conventional buses.

The second type of studies are mainly focused on the impact on the capacity of roads or intersections as well as delay incurred by bus stops. For instance, a weighted-leastsquares regression model was used to estimate the dwell time of buses at stops that associated prediction interval to reduce the negative impacts of nearside bus stops [10]. Furth and SanClemente [11] worked on the impact of bus stop locations on bus delay where buses are running on the near-side, far-side, uphill, downhill of road. By dividing bus delay into service delay and nonservice delay, Xu et al. [12] proposed a delay estimation model for buses at a bus bay stop and a curbside bus stop. Lu et al. [13] concentrated on the delay of buses near a stop when mixed traffic flow was considered by a special cellular automation model. The relationship between delay time and distance from a bus stop to a stop line of intersection, arriving rates, and dwell time of buses, signal circle, was studied [14]. A kinematic wave theory-based model was used to determine where to place a near-side stop to achieve a target level of residual car queuing [15]. Chen et al. [16] developed a computation method on the bus delay at stops in Beijing through statistical analysis.

The existing efforts that considered the benefits from any one perspective of passengers [17], buses [18], and cars [19], and sometimes even the combination of any two, such as the cost of buses and delay time of cars [20], have provided important references for optimizing locations of bus stops. However, there is insufficient research that fully accounts for the influences from some vital factors at the same time, such as the walking distance of passengers, delay time of cars, and travelling time of buses. It is necessary and helpful to make up the gap by implementing a multiobjective analysis.

The rest of this study is organized as follows. A multiobjective optimization model is developed in Section 3 to aim at the shortest total walking distance of passengers, minimum delay time of cars through intersections, and least travelling time of buses. The solution method is given in Section 4. The empirical studies for the Xizhimen bus stops in Beijing and their sensitivity analyses are finally conducted to ensure that the proposed model is effective in Section 5.

\section{Model Formulation}

3.1. Objective Functions. The locations selection of bus stops mainly influences the walking distance of passengers and travelling speed of cars and buses through impact regions. The optimization of total walking distance of passengers, delay time of cars through intersections, and travelling time of buses plays a crucial role in determining an appropriate position for bus stops.

3.1.1. Total Walking Distance of Passengers. Different from common passengers, the walking distance of passengers who want to transfer at the feeder bus stops connecting subways is usually classified into two parts: transfer distance from subways to buses and direct distance to take buses. Thus, the total walking distance of transferring passengers can be expressed by

$$
\begin{aligned}
\min Z_{1} & =W_{1}+W_{2} \\
& =P_{1} * D_{1 x}+P_{2} * D_{2 x}+P_{3} * D_{3 x} \\
& =P_{1} *\left|x-A_{1}\right|+P_{2} * x+P_{3} *\left(A_{2}-x\right),
\end{aligned}
$$

where $W_{1}$ is the total walking distance of passengers transferring from adjacent subways to buses, $W_{2}$ is the total walking distance which passengers take buses through upstream or downstream intersections, $P_{1}$ is the number of passengers who transfer between subways and buses, $P_{2}$ is the number of passengers who come from the upstream intersection adjacent to bus stops, $P_{3}$ is the number of passengers who come from the downstream intersection adjacent to bus stops, $D_{1 x}$ is the distance from bus stops to subway entrances where the abscissa of bus stop center is set to $x, D_{2 x}$ is the distance from bus stops to their adjacent upstream intersection, and $D_{3 x}$ is the distance from bus stops to their adjacent downstream intersection. $A_{1}$ and $A_{2}$ are the abscissas of subway entrance and its adjacent downstream intersection, respectively. The upstream intersection is selected as the origin of horizontal ordinate. The detailed layout including the relative positions of bus stops, adjacent intersections, and subway stations is represented in Figure 1. 


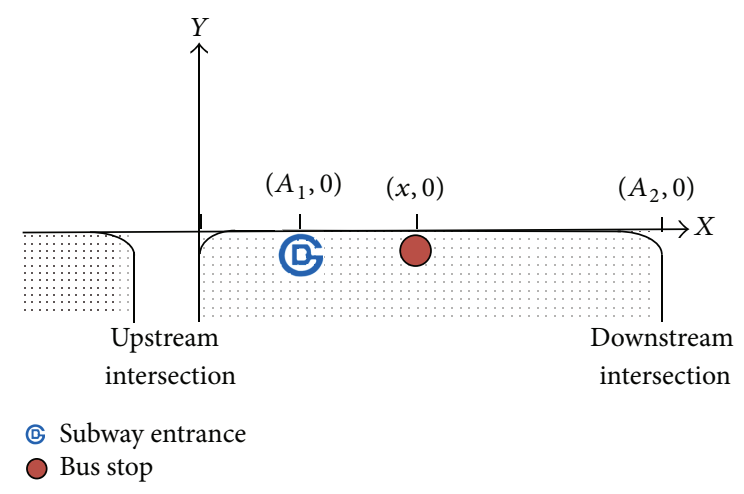

FIGURE 1: Location layout of subway entrance and bus stops.

3.1.2. Delay Time of Cars through Intersections. It will be convenient for passengers to transfer between subways and other transportation modes and gather or disperse in all directions if the locations of bus stops are close to intersections, which is however likely to generate the delay time of private cars and taxis.

The following factors are key parameters in modeling delay at intersections with a bus stop: $L$ is distance between bus stop and stop line (m), $q$ is traffic flow including vehicles and buses at the key lane (vehicles/s), $f$ is the average arrival rate of every bus line at the bus stop (vehicle/s), $B$ is the average boarding and alighting time for passenger at the multiple feeder bus stop (s), $\Omega$ is proportion of time the bus is blocked at the bus stop, which is equal to the value that $f$ multiplies by $B, g$ is effective green times (s), and $c$ is cycle times (s).

The delay of cars at signalized intersections is expressed by the following equation [21]:

$Z_{2}=\frac{c(1-\lambda)^{2}}{2\left(1-\lambda x_{s}\right)}+\frac{x_{s}^{2}}{2 q\left(1-x_{s}\right)}+\frac{x_{b}}{q\left(1-x_{b}\right)}+\alpha_{0} \frac{q^{\alpha_{2}} \Omega^{\alpha_{3}} c^{\alpha_{5}}}{L^{\alpha_{1}} g^{\alpha^{4}}}$.

The delay of cars at unsignalized downstream intersections is expressed by the following equation [21]:

$$
Z_{2}=\frac{c(1-\lambda)^{2}}{2\left(1-\lambda x_{s}\right)}+\frac{x_{s}^{2}}{2 q\left(1-x_{s}\right)}+\frac{x_{b}}{q\left(1-x_{b}\right)}+\alpha_{0} \frac{q^{\alpha_{2}} \Omega^{\alpha_{3}}}{L^{\alpha_{1}}}
$$

where $\lambda$ is the proportion of effective green time $g$ with a cycle time $c$ and is calculated by (4). $\lambda$ is equal to 1 if intersections are unsignalized:

$$
\lambda=\frac{g}{c} .
$$

$x_{s}$ is the degree of key entrance lanes at intersections and can be expressed by the following equation; $s$ is saturation flow:

$$
x_{s}=\frac{q}{(\lambda s)},
$$

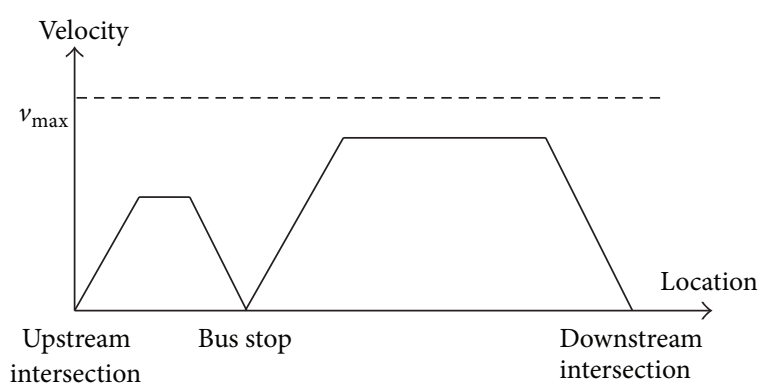

FIGURE 2: Speed profile of buses when bus stops are located near upstream intersection.

where $q$ is the traffic flow volume including vehicles and buses per lane (pcu/s). $x_{b}$ is the degree of saturation at bus stops which can be described as

$$
x_{b}=\frac{q}{[(1-\Omega) s]},
$$

where $\Omega$ is the proportion of time when buses are dwelling at bus stops, whose value is equal to the product of the average arrival rate of buses to bus stops, $f$ (vehicle/s), and the average boarding and alighting time of passengers at bus stops, $B(\mathrm{~s})$. $f$ and $B$ are obtained by

$$
\begin{aligned}
& f=\frac{\sum_{i=1}^{m} f_{i}}{m}, \\
& B=\frac{\sum_{i=1}^{m} B_{i} * n_{i}}{\sum_{i=1}^{m} n_{i}},
\end{aligned}
$$

where $f_{i}$ is the arrival rate of bus berth $i ; B_{i}$ is the average alighting and boarding time of passengers for bus berth $i$; and $n_{i}$ is the number of buses dwelling at bus berth $i(i=$ $1,2,3, \ldots, m)$.

Moreover, $L$ is the distance between bus stops and the vehicle stop line of downstream intersections (m). $\alpha_{0} \sim \alpha_{5}$ are coefficients and values are 106.5, $-0.09,0.07,1.27,-0.53$, and 0.57 , respectively.

3.1.3. Travelling Time of Buses. The influenced area for bus stops is defined as the area that is located between upstream intersection and downstream intersection in this paper. The process of buses passing the area is divided into seven stages, including accelerating to pass upstream intersections, running at a constant speed, decelerating and stopping at bus stops, boarding or alighting of passengers at bus stops, accelerating to leave bus stops, running at a constant speed, and decelerating and stopping before downstream intersections. The speed variation of buses with their locations which are differently positioned between two adjacent intersections is illustrated in Figures 2, 3, and 4.

The total travelling time of buses within the influenced area is computed by the following equation in terms of the above analysis:

$$
Z_{3}=\sum_{j=1}^{7} t_{j},
$$




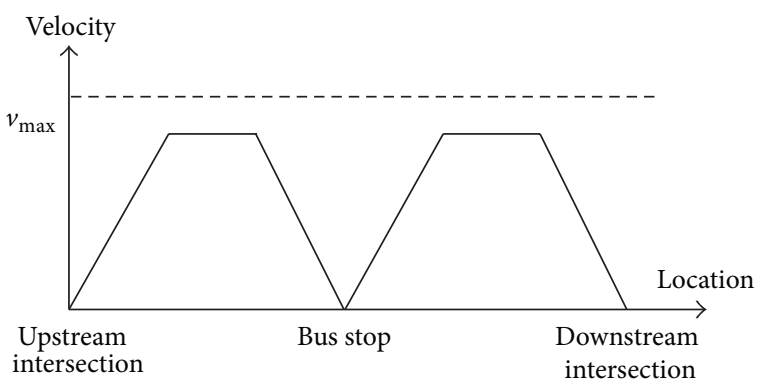

FIGURE 3: Speed profile of buses when bus stops are located equally away from downstream and upstream intersections.

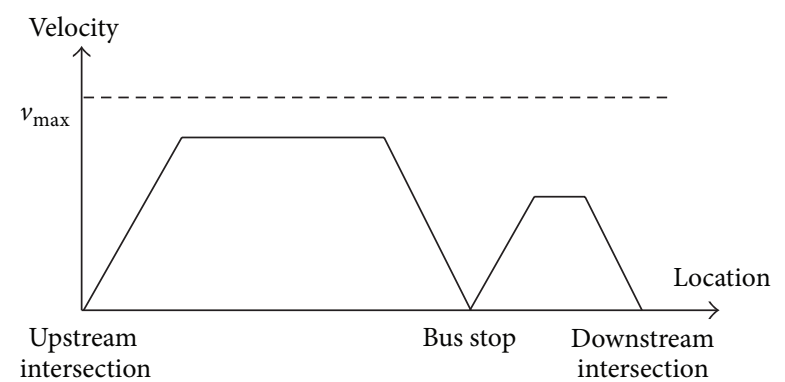

FIGURE 4: Speed profile of buses when bus stops are located near downstream intersection.

where $t_{j}$ is the consumed time of buses within each stage as mentioned above, respectively.

The corresponding travelling distance $S_{j}$ for each stage as introduced before can be calculated by different methods. For the stages where buses are accelerating or decelerating, the travelling distance $S_{j}$ is obtained by

$$
\begin{aligned}
S_{j} & =v_{j, 0} t_{j}+\frac{1}{2} a t_{j}^{2}, \\
v_{j, \max } & =v_{j, 0}+a t_{j},
\end{aligned}
$$

where $j$ is the order number of the stages as shown in Figures 2 to 4 that buses run through $(j=1,3,5$ or 7$) . S_{j}$ is the travel distance of buses with the stage $j . v_{j, 0}$ is the initial travel velocity of buses at the beginning of process $j ; v_{j, \max }$ is the maximum travelling velocity of buses in the stage $j . a$ is the accelerated velocity and is set to $1.4 \mathrm{~m} \cdot \mathrm{s}^{-2}$ [22].
For the stage when buses dwell at stops, the boarding and alighting time of passengers, $t_{4}$, that is, $B$, is obtained by (10) given in terms of [16]:

$$
\begin{aligned}
t_{4} & =T_{\text {curbside }} \\
& = \begin{cases}1.824 * \max \left\{m_{1}, m_{2}, m_{3}\right\}+4.694 & \mathrm{LF}<0.55 \\
2.492 * \max \left\{m_{1}, m_{2}, m_{3}\right\}+3.876 & \mathrm{LF} \geq 0.55\end{cases} \\
t_{4} & =T_{\text {bay-style }} \\
& = \begin{cases}2.219 * \max \left\{m_{1}, m_{2}, m_{3}\right\}+4.359 & \mathrm{LF}<0.7 \\
2.373 * \max \left\{m_{1}, m_{2}, m_{3}\right\}+3.001 & \mathrm{LF} \geq 0.7,\end{cases}
\end{aligned}
$$

where $T_{\text {curbside }}$ and $T_{\text {bay-style }}$ are the dwelling time of buses during boarding and alighting passengers at curbside and bay-style stops, respectively. $m_{1}, m_{2}$, and $m_{3}$ are the number of passengers boarding and alighting at different bus doors. LF is the load factor of buses, which is usually calculated through the ratio of passenger number to bus capacity.

For the stages when buses are running at a constant speed, the corresponding travelling times and distances are calculated by (12). The constant operational velocity is set to $35 \mathrm{~km} \cdot \mathrm{h}^{-1}$, which is equal to $9.7 \mathrm{~m} \cdot \mathrm{s}^{-1}$ [22]:

$$
\begin{aligned}
t_{2}+t_{6} & =\frac{A_{2}-\sum_{j=1,3,5,7} S_{j}}{9.7}, \\
S_{2}+S_{6} & =9.7 *\left(t_{2}+t_{6}\right) .
\end{aligned}
$$

The abscissa of bus stop center $x$ is required to satisfy

$$
x=\sum_{j=1}^{3} S_{j}
$$

3.2. Constraints. The performance of vehicles at upstream intersections will not be affected by queuing buses. Thus, the location of the bus stops is required to be confined within a certain range and the corresponding constraint is expressed by

$$
\max \left\{l_{\text {bus }} \cdot L_{s}\right\} \leq X \leq \min \left\{A_{2}\right\},
$$

where $X$ is the set of alternative locations of bus stops. $l_{\text {bus }}$ is the vehicle length of buses. $L_{s}$ is the number of buses permitted to queue before bus stops.

The constraint indicates that the minimum distance from bus stops to the upstream intersection is more than the permitted maximum length of queuing bus while the maximum distance is less than the road length from upstream to downstream intersections.

The number of buses permitted to queue $L_{s}$ can be calculated through the following equation as the service system of buses is really an $\mathrm{M} / \mathrm{M} / \mathrm{C}$ queuing system:

$$
L_{s}=\frac{\rho(C \rho)^{C}}{C !(1-\rho)^{2}} P(0)+\frac{f}{\mu},
$$


where $C$ is the number of bus berths. The probability without any bus at stops, $P(0)$, is expressed by

$$
P(0)=\left[\sum_{k=0}^{C-1} \frac{1}{k !}\left(\frac{f}{\mu}\right)^{k}+\frac{1}{\left(1-\rho^{C}\right) \cdot C !}\left(\frac{f}{\mu}\right)^{C}\right]^{-1} .
$$

The total arrival rate of buses at bus stops, $f$, is attained through

$$
f=\sum_{i=1}^{n} f_{i}
$$

where $f_{i}$ is the arrival rate of buses at bus stops along the bus route $i$. The average service rate of buses at stops, $f$, is obtained by

$$
\mu=\frac{3600}{B} .
$$

The service intensity of bus stops is expressed by

$$
\rho=\frac{f}{C \mu} .
$$

\section{Solution of the Multiobjective Optimization Model}

The mathematical model for the optimal locations of bus stops connecting subways near urban intersections is proposed as below

$$
\begin{array}{ll}
\min & F(x)=\left[\begin{array}{l}
Z_{1}(x) \\
Z_{2}(x) \\
Z_{3}(x)
\end{array}\right] \\
\text { s.t. } \quad x \in X,
\end{array}
$$

where $x$ is a decision vector containing all continuous variables, $F(x)$ denotes multiple objective functions, $Z_{k}(x)(k=$ $1,2,3)$ gives the $k$ th nonlinear objective function, and $X$ denotes the set of feasible solutions.

For multiobjective problems, a set of Pareto optimal solutions form the Pareto frontier of them. Decision makers (DM) usually select a particular Pareto solution based on additional preference information about the objectives.

4.1. Multiobjective Analysis. The total walking distance of passengers, delay time of cars through intersection, and travel time of buses are given in different units so that they are unable to be measured and compared directly. A normalization formula on the basis of the original Pareto frontier is established as follows:

$$
\bar{Z}^{k}=\frac{Z^{k}-Z_{\min }^{k}}{Z_{\max }^{k}-Z_{\min }^{k}} \quad \bar{Z}^{k} \in[0,1],
$$

where $\bar{Z}^{k}, Z_{\min }^{k}$, and $Z_{\max }^{k}$ are the normalized, maximum, and minimum values of the $k$ th $(k=1,2,3)$ objective, respectively. The original Pareto frontier can be converted to the normative Pareto frontier after the normalization procedure.

The best alternatives under different weights on objectives by the distance-based method can be figured out. The distance-based method is expressed by

$$
\begin{array}{ll}
\min & f=c_{1} \bar{Z}_{1}+c_{2} \bar{Z}_{2}+c_{3} \bar{Z}_{3} \\
\text { s.t. } & c_{1}+c_{2}+c_{3}=1 \\
& 0 \leq c_{1}, c_{2}, c_{3} \leq 1,
\end{array}
$$

where $c_{1}, c_{2}$, and $c_{3}$ are the weight coefficients of three objectives, which represent the preferences of managers or decision makers on the objectives, respectively. The weight coefficients also denote the relative importance of the objectives and are more important when they are more close to 1 .

4.2. Solution Method. There are a large variety of methods to solve multiobjective optimization problems, including exact methods, such as the $\varepsilon$-constraint approach and Tchebycheff algorithm, and heuristic algorithms, such as evolutionary, Tabu search, ant colony, and particle swarm algorithms.

For the multiobjective model in (20), all feasible positions of bus stops, $x$, should lie within the range between $\max \left\{l_{\text {bus }} \cdot L_{s}\right\}$ and $A_{2}$. The model is thus converted into a nonlinear integer programming model as bus stops are permitted actually to set at those positions in meter in practice, which means that $x$ is an integer. The solution tool, Lingo, is employed here to obtain the Pareto frontier of the proposed model and optimal solutions.

\section{Case Studies}

One bus stop in the Xizhimen terminal of Beijing is selected to implement to verify the validity and practicability of the proposed method in case studies. Moreover, a sensitivity analysis of all alternatives on the weights of three objectives is conducted to provide decision-making supports for bus operators.

5.1. Set-Up. The Xizhimen terminal is a large transportation terminal in the northwestern region of Beijing. Passengers can transfer here among five transportation modes, including railway, subway, private cars, taxis, and bicycles. The daily amount of passengers served by the bus stops in the Xizhimen terminal is over 30000 according to the field survey. The layout of the Xizhimen terminal and its surrounding facilities is described in Figure 5.

The bus stop 1 with 3 bus berths is one of busiest bus stops in the Xizhimen terminal which is located on the eastern side of Gaoliang Bridge Street and between two intersections as shown in Figure 5. The stop is 70 and 170 meters away from the upstream and downstream intersection along the Gaoliang Bridge Street. There are two major passenger flows relating to bus stop 1: interchange passengers from/to Line 2 , Line 4 , and Line 13 of subway and those from/to other bus stops. A few of passengers from/to the downstream intersections are not considered in the case studies. 
TABLE 1: Bus and Passenger Data for the proposed model from field survey.

\begin{tabular}{|c|c|c|c|c|c|c|c|}
\hline Title & & & & Data & & & \\
\hline Number of bus line & 85 & 651 & 438 & 87 & 16 & 26 & YT105 \\
\hline Arrival rate (vehicle/hour) & 4 & 10 & 8 & 8 & 12 & 8 & 12 \\
\hline Passenger boarding or alighting time (s) & 100 & 110 & 90 & 130 & 56 & 45 & 52 \\
\hline Number of passengers transferring from/to subway (person) & & & & 1404 & & & \\
\hline $\begin{array}{l}\text { Number of passengers from/to Subway Line } 2 \text { and other bus } \\
\text { stops (person) }\end{array}$ & & & & 936 & & & \\
\hline
\end{tabular}

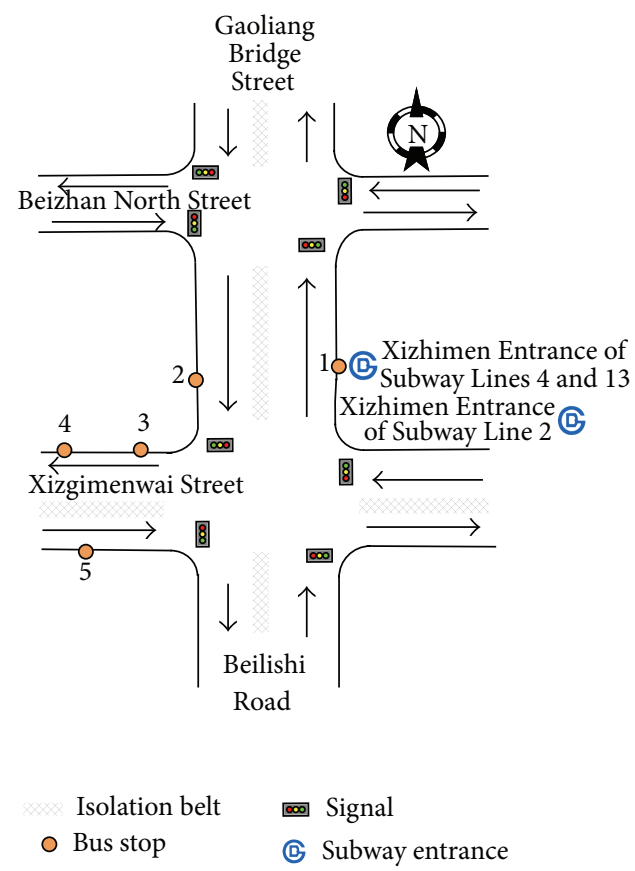

Figure 5: Layout of the Xizhimen bus stop and its surrounding facilities.

The filed data on traffic current situation was collected during the rush hour from 17:30 to 18:30 on December 27, 2013. The effective signal cycle and green time are 140 and 100 seconds at the intersection of Gaoliang Bridge Street and Beizhan North Street. The average length of buses serving passengers here is about 12 meters. The traffic volume and saturated flow rate including buses, cars, and taxis are 526 and $1260 \mathrm{pcu} / \mathrm{lane}$ per hour. Other data on buses and passenger flow are listed in Table 1.

The other basic parameters for the proposed model are calculated in light of the filed survey data and listed in Table 2.

The three objectives of the proposed model under current situation can be computed based on the above field data and calculated parameters. The total walking distance of passengers, delay time of cars through intersection, and travelling time of buses are 93.6 kilometers, 29.7 seconds, and 38.6 seconds, respectively.
TABLE 2: Other basic parameters for the proposed model from survey.

\begin{tabular}{lcccc}
\hline$f$ & $B$ & $\mu$ & $L_{s}$ & $l_{\text {bus }} \cdot L_{s}$ \\
\hline 62 vehicles/h & $79.3 \mathrm{~s}$ & 43.2 vehicles/h & 1.54 & $18.5 \mathrm{~m}$ \\
\hline
\end{tabular}

5.2. Optimization Alternative Analyses. The suitable position of bus stops near intersections is given within a range of 80 to 150 meters away from their upstream intersection in terms of the Code for Design of Urban Road Engineering [23]. To ensure the completeness of this research, the range of possible positions of bus stops is set from 50 to 240 meters. The original Pareto frontier through the proposed model is illustrated in Figure 6.

The variation trend of three objectives with the positions of bus stops is listed in Table 3. " $\nearrow$ " and " У” denote the values of three objectives increase and decrease with the growth of 


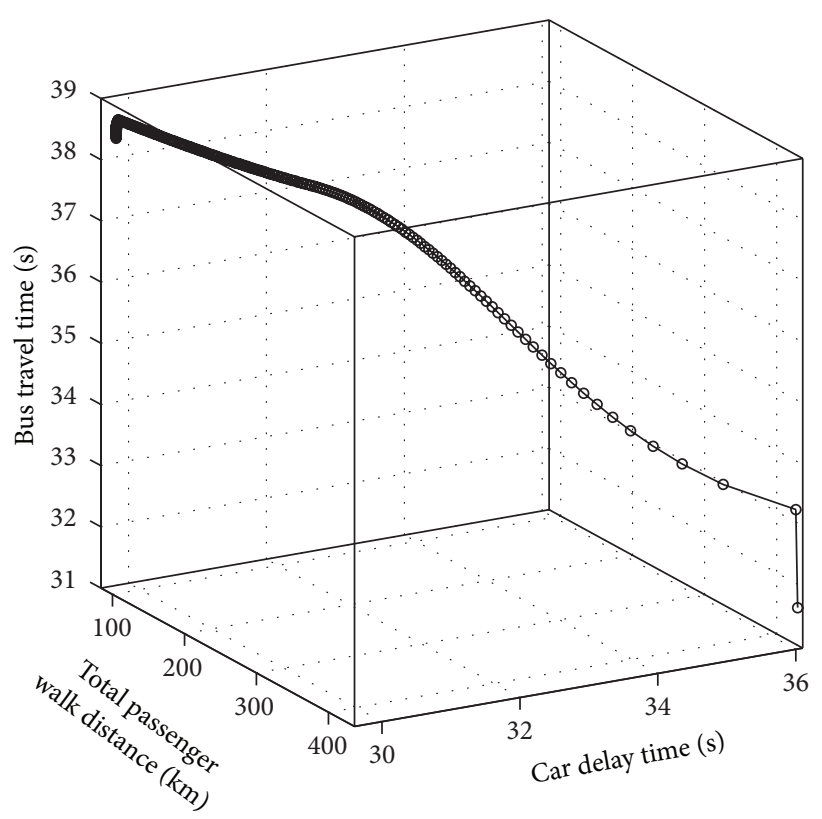

Figure 6: Original Pareto frontier.

TABLE 3: Variation trends of the values of three objectives in the proposed model.

\begin{tabular}{|c|c|c|c|c|c|c|c|c|c|}
\hline \multirow{2}{*}{ Title } & \multicolumn{9}{|c|}{$x$ value } \\
\hline & 50 & - & 67 & - & 90 & - & 174 & - & 240 \\
\hline$Z_{1}$ & $120.45 \mathrm{~km}$ & $\searrow$ & $\searrow$ & $\searrow$ & $\begin{array}{c}84.24 \mathrm{~km} \\
(\text { minimum })\end{array}$ & $\nearrow$ & $\nearrow$ & $\nearrow$ & $\begin{array}{c}435.24 \mathrm{~km} \\
\text { (maximum) }\end{array}$ \\
\hline$Z_{2}$ & $\begin{array}{c}29.62 \mathrm{~s} \\
\text { (minimum) }\end{array}$ & $\nearrow$ & $\nearrow$ & $\nearrow$ & $\nearrow$ & $\nearrow$ & $\nearrow$ & $\nearrow$ & $36.03 \mathrm{~s}$ \\
\hline$Z_{3}$ & $34.61 \mathrm{~s}$ & $\nearrow$ & $\begin{array}{c}38.6 \mathrm{~s} \\
(\mathrm{maximum})\end{array}$ & $38.6 \mathrm{~s}$ & $38.6 \mathrm{~s}$ & $38.6 \mathrm{~s}$ & $38.59 \mathrm{~s}$ & $\searrow$ & $\begin{array}{c}31.67 \mathrm{~s} \\
\text { (minimum) }\end{array}$ \\
\hline
\end{tabular}

$x$, respectively. The maximum and minimum values of three objectives from Table 3 are 435.24 and $84.24 \mathrm{~km}, 36.03$ and 29.62 seconds, and 38.6 and 31.67 seconds, respectively.

The normalization of Pareto frontier is shown in Figure 7.

A group of optimal solutions are obtained and listed in Table 4 under the different combination of weight coefficients according to the preferences of decision makers or managers.

All Pareto solutions for 66 weight combinations are summarized into 5 groups due to $x$ values from Table 4 . The details on the grouping and improvement rates of solutions comparing to the current position of the bus stop, that is, $x$ is 70 , are listed in Table 5. It indicates that weight combinations have remarkable influences on optimal solutions. For example, if decision makers pay more attention to the reduction of the delay of cars through intersection and the travelling time of buses, the optimal position of bus stops will tend to be close to the upstream and downstream intersection, respectively. If the total walking distance of passengers is considered most, the optimal position will be located near the subway stations and keep a certain distance from adjacent intersections. Thus the balanced optimal position of bus stops is here recommended to be 90 meters away from the upstream intersection due to the average improvement rates of three objectives in Table 5.

\section{Conclusion}

Locations of bus stops connecting subways are much crucial to improve the efficiency and level of service of bus operations. A multiobjective optimization model to determine suitable locations of bus stops is proposed in this study considering the total walking distance of passengers, delay time of cars through intersections, and travelling time of buses between adjacent intersections. The proposed model is available and effective to determine locations of bus stops through case studies where an empirical study on the bus stop at Xizhimen in Beijing is carried out. The balanced optimal location of bus stops connecting to subways is recommended to be near its upstream intersection and subway station 
TABLE 4: Optimal solutions under different weights.

\begin{tabular}{|c|c|c|c|c|}
\hline Number & $c_{1}$ & $c_{2}$ & $c_{3}$ & $x$ \\
\hline 1 & \multirow{11}{*}{0} & 0 & 1 & 240 \\
\hline 2 & & 0.1 & 0.9 & 240 \\
\hline 3 & & 0.2 & 0.8 & 240 \\
\hline 4 & & 0.3 & 0.7 & 240 \\
\hline 5 & & 0.4 & 0.6 & 240 \\
\hline 6 & & 0.5 & 0.5 & 50 \\
\hline 7 & & 0.6 & 0.4 & 50 \\
\hline 8 & & 0.7 & 0.3 & 50 \\
\hline 9 & & 0.8 & 0.2 & 50 \\
\hline 10 & & 0.9 & 0.1 & 50 \\
\hline 11 & & 1 & 0 & 50 \\
\hline 12 & \multirow{10}{*}{0.1} & 0 & 0.9 & 240 \\
\hline 13 & & 0.1 & 0.8 & 240 \\
\hline 14 & & 0.2 & 0.7 & 240 \\
\hline 15 & & 0.3 & 0.6 & 239 \\
\hline 16 & & 0.4 & 0.5 & 50 \\
\hline 17 & & 0.5 & 0.4 & 50 \\
\hline 18 & & 0.6 & 0.3 & 50 \\
\hline 19 & & 0.7 & 0.2 & 50 \\
\hline 20 & & 0.8 & 0.1 & 50 \\
\hline 21 & & 0.9 & 0 & 50 \\
\hline 22 & \multirow{9}{*}{0.2} & 0 & 0.8 & 240 \\
\hline 23 & & 0.1 & 0.7 & 240 \\
\hline 24 & & 0.2 & 0.6 & 240 \\
\hline 25 & & 0.3 & 0.5 & 240 \\
\hline 26 & & 0.4 & 0.4 & 50 \\
\hline 27 & & 0.5 & 0.3 & 50 \\
\hline 28 & & 0.6 & 0.2 & 50 \\
\hline 29 & & 0.7 & 0.1 & 50 \\
\hline 30 & & 0.8 & 0 & 50 \\
\hline 31 & \multirow{3}{*}{0.3} & 0 & 0.7 & 240 \\
\hline 32 & & 0.1 & 0.6 & 240 \\
\hline 33 & & 0.2 & 0.5 & 240 \\
\hline 34 & \multirow{5}{*}{0.3} & 0.3 & 0.4 & 50 \\
\hline 35 & & 0.4 & 0.3 & 50 \\
\hline 36 & & 0.5 & 0.2 & 50 \\
\hline 37 & & 0.6 & 0.1 & 50 \\
\hline 38 & & 0.7 & 0 & 50 \\
\hline 39 & \multirow{7}{*}{0.4} & 0 & 0.6 & 240 \\
\hline 40 & & 0.1 & 0.5 & 240 \\
\hline 41 & & 0.2 & 0.4 & 90 \\
\hline 42 & & 0.3 & 0.3 & 90 \\
\hline 43 & & 0.4 & 0.2 & 90 \\
\hline 44 & & 0.5 & 0.1 & 90 \\
\hline 45 & & 0.6 & 0 & 71 \\
\hline 46 & \multirow{4}{*}{0.5} & 0 & 0.5 & 90 \\
\hline 47 & & 0.1 & 0.4 & 90 \\
\hline 48 & & 0.2 & 0.3 & 90 \\
\hline 49 & & 0.3 & 0.2 & 90 \\
\hline
\end{tabular}

TABLE 4: Continued.

\begin{tabular}{lcccc}
\hline Number & $c_{1}$ & $c_{2}$ & $c_{3}$ & $x$ \\
\hline 50 & & 0.4 & 0.1 & 90 \\
51 & & 0.5 & 0 & 90 \\
\hline 52 & 0.6 & 0.1 & 0.4 & 90 \\
53 & 0.2 & 0.3 & 90 \\
54 & & 0.3 & 0.2 & 90 \\
55 & 0.4 & 0.1 & 90 \\
56 & & 0 & 0.3 & 90 \\
\hline 57 & & 0.1 & 0.2 & 90 \\
58 & 0.7 & 0.2 & 0.1 & 90 \\
59 & & 0.3 & 0 & 90 \\
60 & & 0 & 0.2 & 90 \\
\hline 61 & 0.8 & 0.1 & 0.1 & 90 \\
62 & & 0.2 & 0 & 90 \\
63 & & 0 & 0.1 & 90 \\
\hline 64 & 0.9 & 0.1 & 0 & 90 \\
65 & 1 & 0 & 0 & 90 \\
\hline 66 & & & &
\end{tabular}

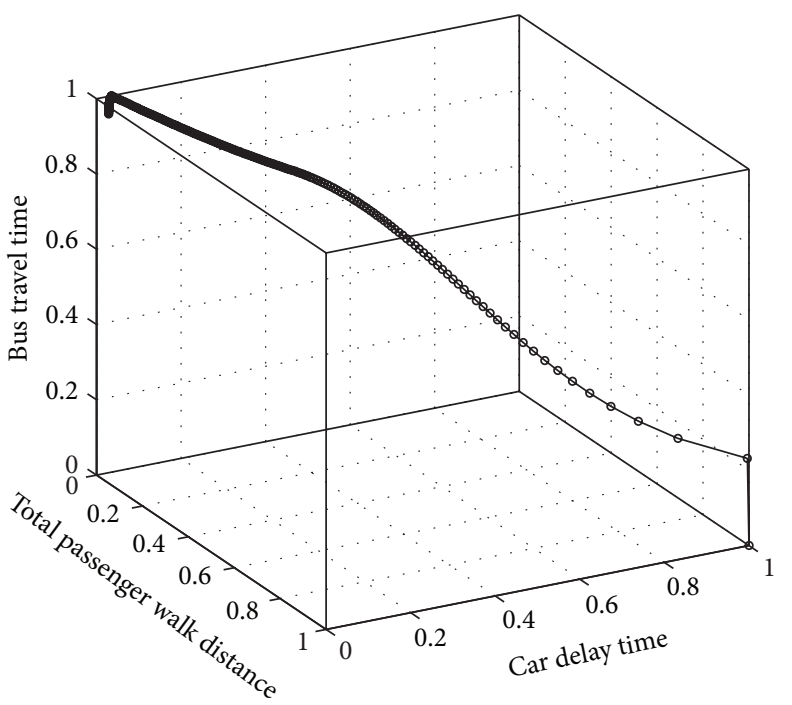

Figure 7: Normalized Pareto frontier.

through this study when it meets the requirement from the Code for Design of Urban Road Engineering [23].

\section{Conflict of Interests}

The authors declare that there is no conflict of interests regarding the publication of this paper. 
TABLE 5: Details on the grouping and average improvement rates of the optimal solutions.

\begin{tabular}{lcccc}
\hline$x$ & Number of Pareto solutions & \multicolumn{2}{c}{ Average improvement rates of different objectives } \\
Objective 2 & $0.36 \%$ & $-5.40 \%$ \\
\hline 50 & 22 & $23 \%$ & $0.02 \%$ & $0.00 \%$ \\
71 & 1 & $-0.7 \%$ & $0.41 \%$ & $0.00 \%$ \\
90 & 25 & $-10 \%$ & $21 \%$ & $-14.1 \%$ \\
239 & 1 & $363 \%$ & $21 \%$ & $-18.6 \%$ \\
240 & 17 & $365 \%$ & & \\
\hline
\end{tabular}

\section{Acknowledgments}

The authors are grateful to the National Basic Research Program of China (2012CB725406) and the National Natural Science Foundation of China (71001006 \& 71131001) for their financial supports on this work.

\section{References}

[1] J. Gibson, I. Baeza, and L. Willumsen, "Bus-stops, congestion and congested bus-stops," Traffic Engineering and Control, vol. 30, no. 6, pp. 291-302, 1989.

[2] S. Yagar and M. A. P. Jacques, "Representing the effects of transit stops at signalized intersections," in Proceedings of the International Symposium on Highway Capacity and Level of Service, pp. 485-492, Karlsruhe, Germany, July 1991.

[3] H. S. Levinson and K. R. St. Jacques, "Bus lane capacity revisited," Transportation Research Record, no. 1618, pp. 189-199, 1998.

[4] Transportation Research Board of the National Academy of Sciences, Highway Capacity Manual 2010, Transportation Research Board of the National Academy of Sciences, Washington, DC, USA, 2010.

[5] E. S. Savas, "On equity in providing public services," Management Science, vol. 24, no. 8, pp. 800-808, 1978.

[6] Á. Ibeas, L. Dell'Olio, B. Alonso, and O. Sainz, "Optimizing bus stop spacing in urban areas," Transportation Research Part E: Logistics and Transportation Review, vol. 46, no. 3, pp. 446-458, 2010.

[7] M. H. Hafezi and A. Ismail, "Interaction between bus stops location and traffic on bus operation," Applied Mechanics and Materials, vol. 97-98, pp. 1185-1188, 2011.

[8] J.-Q. Li, "Match bus stops to a digital road network by the shortest path model," Transportation Research C: Emerging Technologies, vol. 22, pp. 119-131, 2012.

[9] Y. C. Hu, Q. Zhang, and W. P. Wang, "A model layout region optimization for feeder buses of rail transit," Procedia-Social and Behavioral Sciences, vol. 43, pp. 773-780, 2012.

[10] W. Kim and L. R. Rilett, "Improved transit signal priority system for networks with nearside bus stops," Transportation Research Record, no. 1925, pp. 205-214, 2005.

[11] P. G. Furth and J. L. SanClemente, "Near side, far side, uphill, downhill: impact of bus stop location on bus delay," Transportation Research Record, no. 1971, pp. 66-73, 2006.

[12] Z. Xu, V. K. Akpakli, and X.-K. Yang, "A study on the bus delay model at bus stops," in Proceedings of the 9th International Conference of Chinese Transportation Professionals (ICCTP '09), pp. 3062-3071, August 2009.

[13] L. Lu, Y. Su, D. Yao, L. Peng, M. Ding, and R. Xu, "The delay of bus near a stop when mixed traffic flow is considered," in
Proceedings of the IEEE Intelligent Vehicles Symposium, vol. 4, pp. 1104-1109, June 2010.

[14] Y. Sui, F.-J. Shao, R.-C. Sun, and J.-S. Li, "Modeling of traffic flow at signalized intersection with bus stop downstream," Advances in Information Sciences and Service Sciences, vol. 3, no. 7, pp. 4451, 2011.

[15] W. Gu, M. J. Cassidy, V. V. Gayah, and Y. Ouyang, "Mitigating negative impacts of near-side bus stops on cars," Transportation Research Part B: Methodological, vol. 47, pp. 42-56, 2013.

[16] S. Chen, R. Zhou, Y. Zhou, and B. Mao, "Computation on bus delay at stops in Beijing through statistical analysis," Mathematical Problems in Engineering, vol. 2013, Article ID 745370, 9 pages, 2013.

[17] S. I. Chien and Z. Qin, "Optimization of bus stop locations for improving transit accessibility," Transportation Planning and Technology, vol. 27, no. 3, pp. 211-227, 2004.

[18] S. C. Wirasinghe and N. S. Ghoneim, "Spacing of bus-stops for many to many travel demand," Transportation Science, vol. 15, no. 3, pp. 210-221, 1981.

[19] Y. Xiaobao, H. Mei, G. Hongwei, and G. Liang, "Car travel time estimation near a bus stop with non-motorized vehicles," International Journal of Computational Intelligence Systems, vol. 4, no. 6, pp. 1350-1357, 2011.

[20] J. L. Moura, B. Alonso, Á. Ibeas, and F. J. Ruisánchez, "A twostage urban bus stop location model," Networks and Spatial Economics, vol. 12, no. 3, pp. 403-420, 2012.

[21] S. C. Wong, H. Yang, W. S. A. Yeung, S. L. Cheuk, and M. K. Lo, "Delay at signal-controlled intersection with bus stop upstream," Journal of Transportation Engineering, vol. 124, no. 3, pp. 229-234, 1998.

[22] Z. J. Zou, Road Traffic Simulation Research, Tongji University, Shanghai, China, 2001.

[23] Ministry of Housing and Urban-Rural Development of the People's Republic of China, The Code for Design of Urban Road Engineering, (CJJ37-2012), Ministry of Housing and UrbanRural Development of the People's Republic of China, Beijing, China, 2012 (Chinese). 


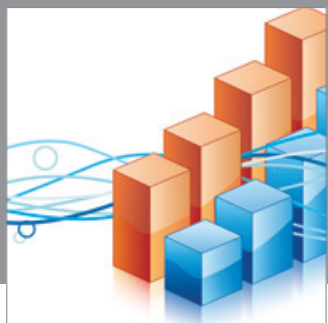

Advances in

Operations Research

mansans

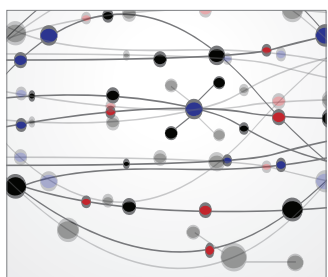

The Scientific World Journal
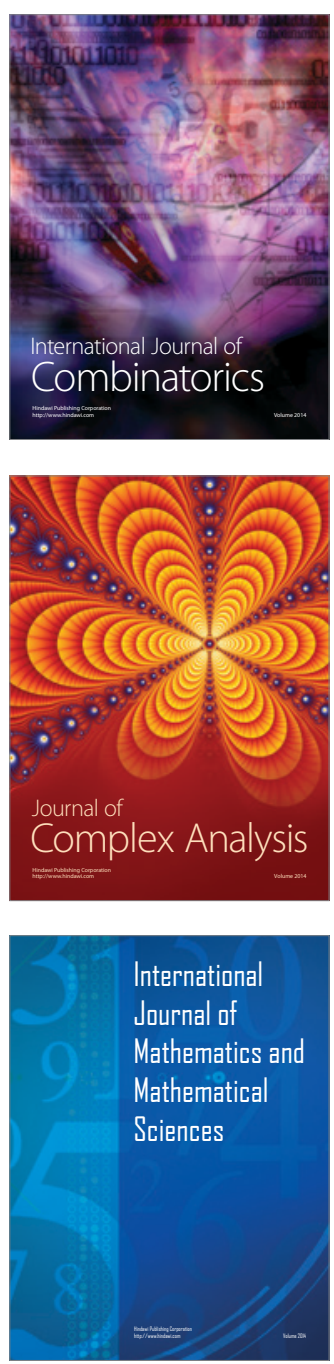
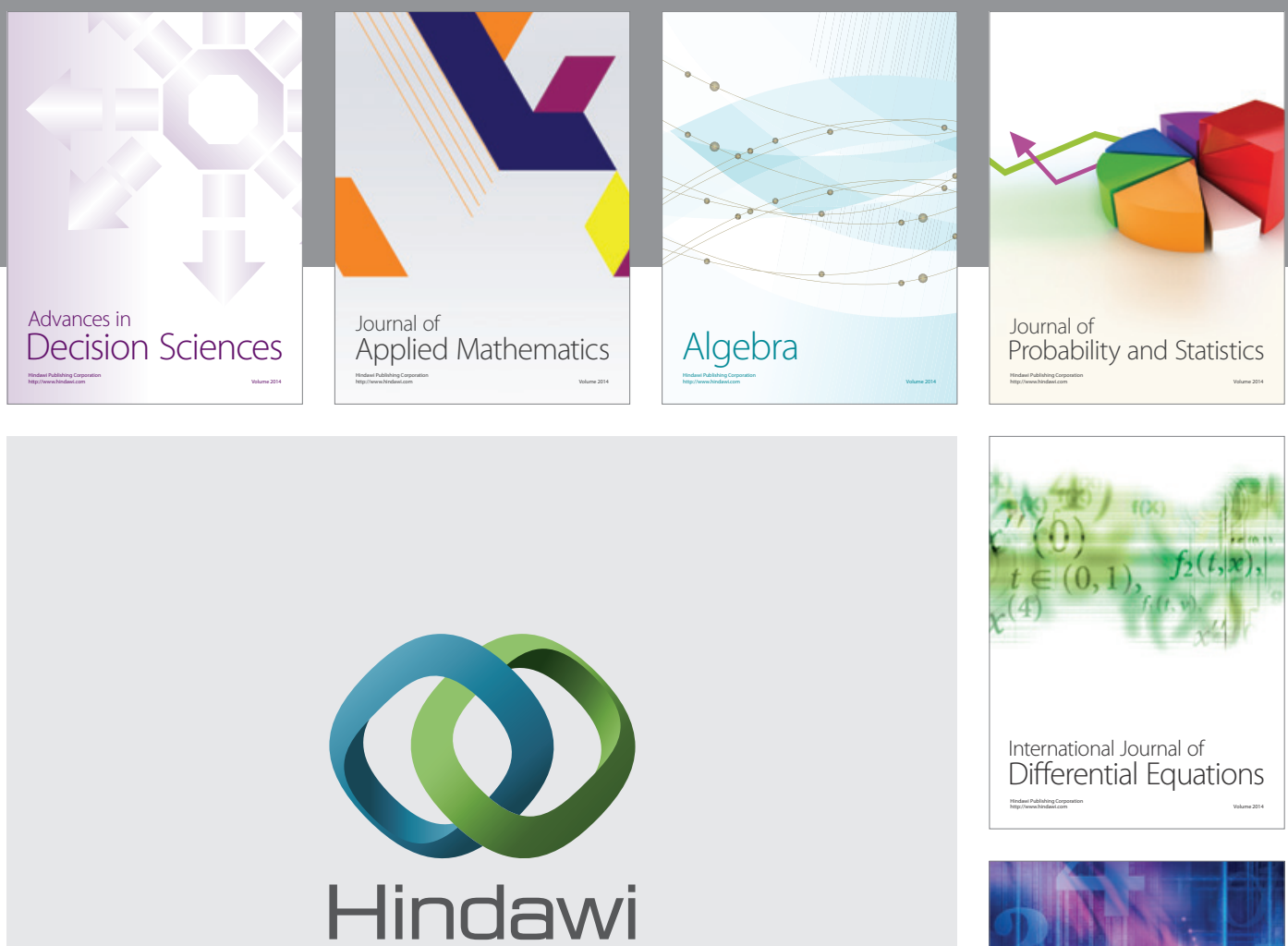

Submit your manuscripts at http://www.hindawi.com
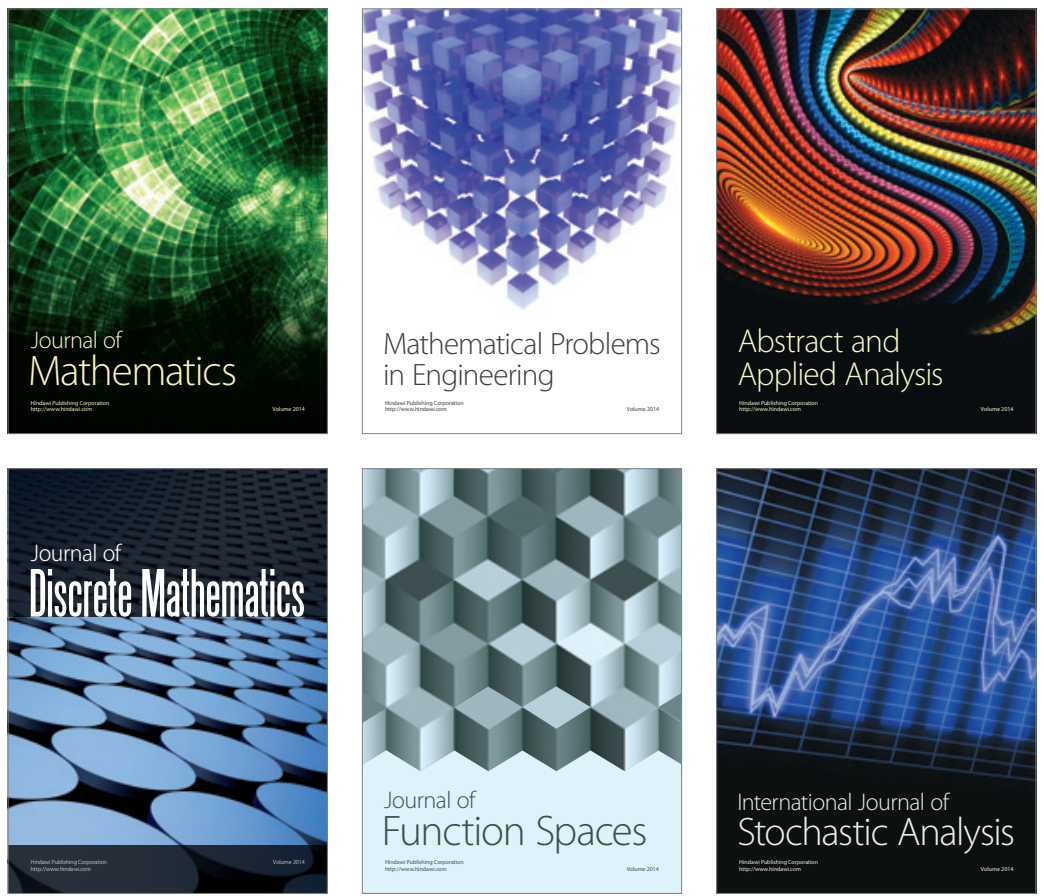

Journal of

Function Spaces

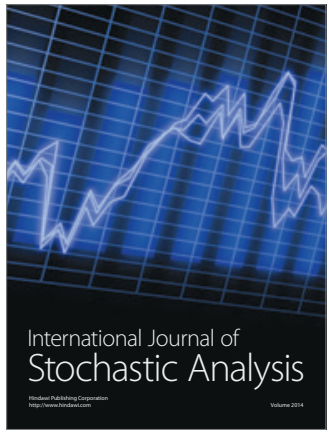

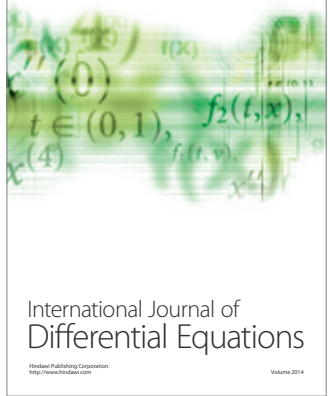
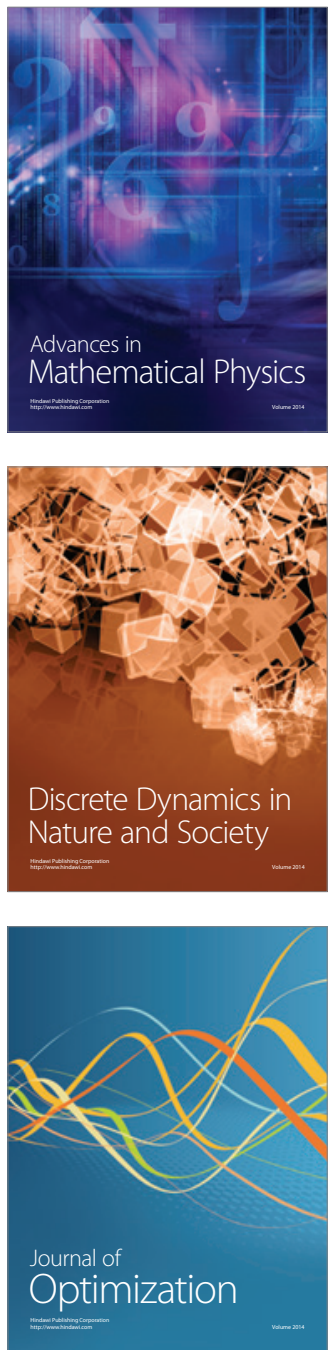